University of Rhode Island

DigitalCommons@URI

Open Access Master's Theses

2021

\title{
THE ROLE OF PERCEIVED SOCIAL SUPPORT AS A MEDIATOR IN THE RELATIONSHIP BETWEEN CHILDHOOD TRAUMA AND SOCIAL ANXIETY
}

Katharine E. Musella

University of Rhode Island, kmusella@uri.edu

Follow this and additional works at: https://digitalcommons.uri.edu/theses

\section{Recommended Citation}

Musella, Katharine E., "THE ROLE OF PERCEIVED SOCIAL SUPPORT AS A MEDIATOR IN THE RELATIONSHIP BETWEEN CHILDHOOD TRAUMA AND SOCIAL ANXIETY" (2021). Open Access Master's Theses. Paper 1958.

https://digitalcommons.uri.edu/theses/1958

This Thesis is brought to you for free and open access by DigitalCommons@URI. It has been accepted for inclusion in Open Access Master's Theses by an authorized administrator of DigitalCommons@URI. For more information, please contact digitalcommons-group@uri.edu. 
THE ROLE OF PERCEIVED SOCIAL SUPPORT AS A MEDIATOR IN THE RELATIONSHIP BETWEEN CHILDHOOD TRAUMA AND SOCIAL ANXIETY

BY KATHARINE E. MUSELLA

\begin{abstract}
A THESIS SUBMITTED IN PARTIAL FULFILLMENT OF THE REQUIREMENTS FOR THE DEGREE OF MASTER OF SCIENCE IN PSYCHOLOGY
\end{abstract}

UNIVERSITY OF RHODE ISLAND

2021 


\title{
MASTER OF SCIENCE THESIS
}

\author{
OF \\ KATHARINE MUSELLA
}

\section{APPROVED:}

Thesis Committee:

Major Professor Ellen Flannery-Schroeder

Andrea Paiva
Diane Martins
Brenton DeBoef
DEAN OF THE GRADUATE SCHOOL

UNIVERSITY OF RHODE ISLAND

2021 


\begin{abstract}
Traumatic childhood experiences (physical abuse and neglect, emotional abuse and neglect, and sexual abuse) have increasingly high incidence rates and can be predictive of negative health outcomes, such as social anxiety. Although the relationship between childhood trauma and social anxiety has been documented, additional research is necessary to understand the mechanisms underlying this relationship. The current study hypothesized that social support, the experience of being valued, respected, cared about and loved by individuals present in a person's life, would mediate the relationship between childhood trauma and social anxiety in a sample of college students $(n=221)$. Furthermore, it was hypothesized that gender would moderate the relationship between childhood trauma and social anxiety. The current study analyzed emotional abuse (EA), emotional neglect (EN), physical abuse (PA), physical neglect (PN), and sexual abuse (SA) separately. Results indicated that EA, EN, PN, and PA were significant predictors of social support, and social support was a significant predictor of social anxiety; therefore, social support did serve as a mediator for the relationship between childhood trauma and social anxiety. However, findings revealed that gender did not moderate the relationship between childhood trauma and social anxiety. Limitations of the current study as well as future directions are discussed.
\end{abstract}




\section{ACKNOWLEDGMENTS}

First and foremost, I would like to extend my thanks and gratitude to my major professor, Dr. Ellen Flannery-Schroeder, for her continuous support and mentorship throughout this process. She has provided the data and tools necessary for the completion of this thesis and has always gone above and beyond her duties as a faculty member to encourage and instill confidence in me. I am utterly grateful for her wisdom, warmth and positive energy in my life.

I would also like to extend my gratitude to my thesis committee members, Dr. Andrea Paiva and Dr. Diane Martins, and my committee chair, Dr. Nilton Porto, for their valuable feedback and input throughout this process. Their expertise and guidance were integral to the completion of this project.

I would like to send thanks and gratitude to my family for the boundless amounts of support they have given me throughout my life and graduate school. Their love, encouragement, and humor have helped me achieve my goals and am genuinely so grateful to have them in my life.

Lastly, I would like to acknowledge my dad who encouraged me to pursue my dreams, and was always there to offer words of encouragement as I navigated the waters of my professional and personal life. Although I can no longer talk with him to celebrate my achievements, I know he would be proud of this milestone. I think of him, and miss him every day, and this thesis is for him. 


\section{TABLE OF CONTENTS}

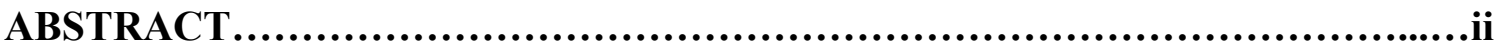

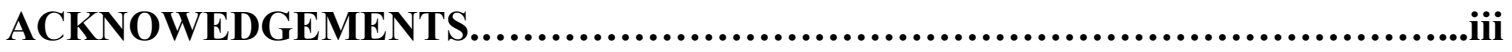

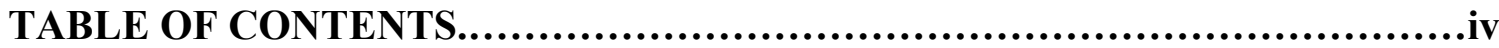

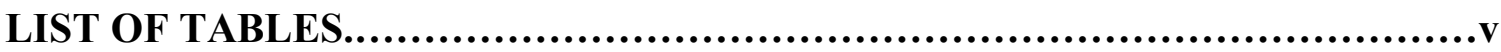

LIST OF FIGURES..............................................................

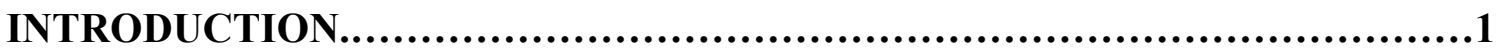

METHOD........................................................................

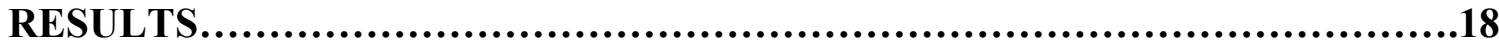

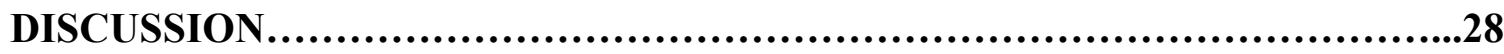

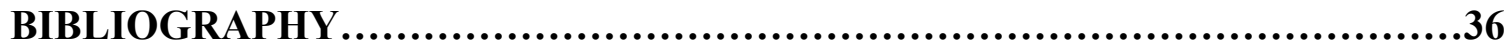




\section{LIST OF TABLES}

TABLE

PAGE

Table 1. Demographic Information of Overall Sample..............................14

Table 2. Severity Cut-off Scores for CTQ subscales............................... 16

Table 3. Ranges, Means, and Standard Deviations for Primary Scales in Overall Sample.17

Table 4. Distribution of CTQ Scores......................................... 18

Table 5. Distribution of SPIN Scores.......................................... 18

Table 6. Distribution of MSPSS Scores............................................... 18

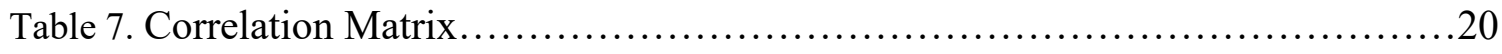

Table 8. Means and Standard Deviations for Study Variables by Gender................21 


\section{LIST OF FIGURES}

FIGURE

PAGE

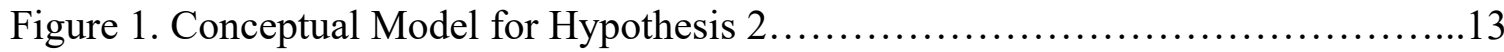

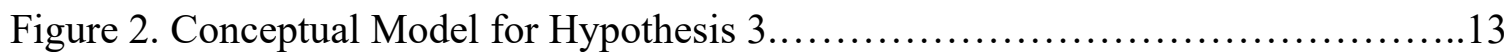

Figure 3. Results of Hierarchical Regression Analyses for the relationships between

Emotional Abuse, Perceived Social Support and Social Anxiety......................24

Figure 4. Results of Hierarchical Regression Analyses for the relationships between

Emotional Neglect, Perceived Social Support and Social Anxiety......................24

Figure 5. Results of Hierarchical Regression Analyses for the relationships between

Physical Abuse, Perceived Social Support and Social Anxiety........................25

Figure 6. Results of Hierarchical Regression Analyses for the relationships between

Physical Neglect, Perceived Social Support and Social Anxiety.....................25 


\section{Statement of the Problem}

\section{Introduction}

Traumatic childhood experiences (physical abuse and neglect, emotional abuse and neglect, and sexual abuse) have received international attention in recent years, not only due to the potentially distressing and lasting effects traumatic childhood experiences can have on individuals, but also because of the increasing evidence that there is an ongoing rise in incidence rates (Beilharz et al., 2019). Children who have been exposed to trauma have been linked to environments that can contribute to poorer quality of life and functioning. Prior research has indicated that childhood trauma has higher incidence races in families that have lower parental education, are below the poverty level, and experience increased life stressors (Klest, 2012; Rosenthal et al., 2009). Further, there have been associations between childhood trauma and the familial structure specifically, a deficiency of family cohesion, unstable parent-child relationships, and households with parents who are abusing substances (Higgins \& McCabe, 2000; Pears et al., 2008). Prevalence rates in some research studies have indicated that childhood trauma is frequently underreported (Goldsmith et al., 2004). Copeland and colleagues (2007) postulated that more than $50 \%$ of children between the ages of 9-16 have been exposed to some form of trauma. Children exposed to trauma have been found to have an increased risk to developing psychiatric disorders including anxiety, mood, and psychotic disorders (Beilharz et al., 2019; Heim \& Nemeroff, 2011; Schäfer et al., 2010). Further, childhood trauma has been related to increased difficulty in interpersonal relationships in adolescence and young adulthood, higher frequency of somatic complaints and poor academic performance (Alink \& Egeland, 2013; Smith et al., 2012; Schäfer et al., 2010). 
Gender differences have been found in prevalence rates, types of abuse experienced, and the symptomatology related to these traumatic experiences (Pruessner et al., 2018; Gwadz et al., 2007). While traumatic childhood experiences can significantly impact both men and women, there has been increasing evidence to suggest that women are more likely to experience and report sexual abuse as well as exhibit a greater number of Posttraumatic Stress Disorder (PTSD) symptoms (Tolin \& Foa, 2006). In 2004, Thompson and colleagues found that physical abuse was more prevalent among men compared to women; however, significantly poorer health outcomes in adulthood were found among women versus men (Thompson et al., 2004). Yet, a significant amount of this research has been conducted with clinical populations or individuals who are part of disadvantaged groups. Therefore, the generalizability of these findings beyond these groups is limited.

It has been well documented that early adverse life events can significantly impact a child's emotional, social, and physical development and be significantly predictive of the development of mental health issues later in life, including, but not limited to, anxiety - among the most prevalent disorders in the United States, affecting millions of individuals with mild to severe impairment, and leading to increased utilization and spending in health services (National Institute of Mental Health [NIMH], 2017). Data from the National Comorbidity Survey Replication (NCS-R) demonstrated that social anxiety disorder was the third most common psychiatric condition following major depression and alcohol dependence (Kessler et al., 2005). Specifically, the survey found that an estimated $9.1 \%$ of U.S. adults between the ages of 18-29 had been diagnosed with social anxiety disorder in the past year (NIMH, 2017). Social anxiety disorder (SAD), an 
anxiety disorder associated with significant functional impairment and distress, impacts approximately 15 million individuals in the United States each year (Kuo et al., 2011; Kessler et al., 2005). Social anxiety is often characterized by a constant fear of social performance situations in which an individual has a potential risk of embarrassment, scrutiny, or humiliation by others (American Psychiatric Association [APA], 2000). Prior research has indicated gender disparities in the prevalence of anxiety disorders, including SAD. Women are disproportionately more likely to receive lifetime diagnoses and demonstrate increased disability rates compared to men (McLean et al., 2011; APA, 2013; Cross et al., 2011). There is substantial evidence that childhood trauma is significantly correlated with anxiety. Despite this strong research base, there is a need for research evaluating the specific factors that predict the development and maintenance of anxiety disorders, including social anxiety (Kuo et al., 2011).

Social support refers to the experience of being valued, respected, cared about and loved by individuals present in a person's life (Roohafza et al., 2014). Social support aids in promoting a better quality of life and serves as a protective factor in the face of life stressors, particularly among children who have experienced traumatic events (Roohafza et al., 2014; Evans et al., 2013). Prior research has indicated that social support and anxiety are inversely related, such that higher perceived social support is associated with lower levels of anxiety. Further, research on gender differences in perceived social support has been somewhat inconclusive, with some studies citing that women may provide and receive more social support than men (Barnett et al., 2020; Soman et al., 2016). Prior studies have indicated that women tend to disclose more frequently and seek out emotional support on a more consistent basis than men, thus, having a greater 
perception of social support (Barnett et al., 2020; Neff \& Karney, 2005). No studies to date have examined the relationship amongst childhood trauma, social support, and social anxiety. The proposed study aimed to (1) evaluate perceived social support as a possible mediator for the relationship between childhood trauma and social anxiety, and (2) evaluate gender as a possible moderator for the relationship between childhood trauma and social anxiety.

\section{Review of the Literature}

Childhood Trauma. Incidence rates of traumatic childhood experiences are on the rise and have been found to predict various mental health disorders (Beilharz et al., 2019; Heim \& Nemeroff 2001). Felitti and colleagues (1998) conducted one of the most noteworthy studies assessing the effect of childhood trauma on long-term physical and mental health, the Adverse Childhood Experiences (ACEs) study. This study comprised 9,508 adults that completed a standardized medical evaluation and answered questions pertaining to health status, disease, and risk behaviors. Felitti and colleagues specifically examined seven categories of ACEs (psychological, physical, or sexual abuse, violence against mother, living with a household member who was substance abusers, ever imprisoned, mentally ill or suicidal). Findings from the study indicated that traumatic childhood experiences are prevalent in the United States population (Felitti et al. 1998). Further, the researchers also found a "dose-response" relationship between ACEs and social and health issues (Felitti et al. 1998).

Gender Differences in Childhood Trauma. While traumatic childhood experiences significantly impact both men and women, there is increasing evidence of gender differences among rates and types of childhood trauma experienced (Pruessner et 
al., 2018; Gwadz et al., 2007; Fisher et al., 2009; Vahl et al., 2015). Fisher and colleagues (2009), in a clinical sample of 390 patients diagnosed with a first episode of psychosis, found that women were twice as likely to report either physical or sexual abuse compared with non-psychotic controls; however, this association was not found among men. In a sample of 341 detained adolescents (54\% female), Vahl and colleagues (2015) found that females reported higher rates of maltreatment experiences and internalizing and externalizing mental health problems than males. Additionally, authors found that in both genders emotional abuse was associated with internalizing and externalizing disorders, potentially having a more significant impact on mental health versus other types of abuse. However, differential gender effects were found with sexual abuse reports linked to internalizing symptomatology in females and externalizing symptomatology in males. A majority of the studies examining gender differences in childhood trauma have been conducted with a clinical or at-risk sample. At present, there is a paucity of studies investigating the differences among non-clinical samples.

Childhood Trauma and Social Anxiety. Prior research has suggested that early childhood trauma may be a contributing factor leading to SAD. Recent models have postulated that SAD results from an individual having both a biological vulnerability and negative social learning experiences (Heimberg et al., 2010; Clark \& Wells, 1995; Kuo et al., 201). In recent years, childhood trauma, a particular environmental social learning disruption, has gained substantial attention due to the lasting impacts it can have on child development. In early childhood, the brain is developing at a significant rate and is particularly vulnerable to adverse environmental experiences such as emotional, physical, and sexual abuse and neglect (Spenrath et al., 2011; Heim \& Nemeroff, 2001). Traumatic 
events experienced during this impressionable time can have lasting impacts on behavioral, social, emotional, social, physical, and cognitive development (Bremne \& Vermetten, 2001; Middlebrooks \& Audage, 2008). A systematic review evaluating the relationship between early life stress (ELS), defined as traumatic experiences during childhood and adolescence, and psychiatric disorders in adulthood was conducted by Carr and colleagues (2013). The review analyzed 44 articles, and results were consistent with previous literature findings of the strong relationship between childhood trauma and anxiety.

Research has sought to understand mechanisms that may explain the relationship between childhood trauma and the development of psychiatric disorders. Research has placed a particular focus on the strong relationship between childhood trauma and anxiety. One proposed mechanism used to explain the relationship is emotion dysregulation (Huh et al., 2017; Poole et al., 2017). In a clinical study, Huh and colleagues (2017) found that an emotional regulation strategy mediated the relationship between childhood trauma and current depression and anxiety levels. Additionally, research has indicated that rumination, a maladaptive cognitive emotion regulation strategy where an individual engages in obsessive thinking about an idea, situation, or a choice that interferes with adaptive functioning, mediates childhood trauma and symptoms of anxiety in adulthood (Huh et al., 2017). Another mechanism that has been studied as a potential mediator in the relationship of childhood trauma and adult symptoms of anxiety is psychological resilience (Poole et al., 2017; Soenke et al., 2010). Resilience can be defined as the ability to sustain adaptive functioning following the experience of stress or trauma (Poole et al., 2017). Prior research has indicated that 
resilience protects against the development of anxiety in the context of childhood trauma (Poole et al., 2017; Soenke et al., 2010). In recent years, there has been an increased focus to better understand the relationship between childhood trauma and social anxiety. Studies that have investigated childhood trauma and SAD have found parental rejection and absence of emotional warmth are associated with SAD (Kuo et al., 2011). Additionally, studies investigating adults with SAD have reported finding parental use of negative forms of discipline, such as shame, in their childhoods (Bruch \& Heimberg, 1994). While previous research studies have investigated mediators such as emotion dysregulation, rumination and psychological resilience, none of them have clearly defined the relationship between childhood trauma and social anxiety. Therefore, it is critical that we identify additional mediators to more fully explain this relationship.

Gender Differences in Social Anxiety. Throughout the lifespan, females are disproportionally more likely to develop SAD than men (McLean et al., 2011; APA, 2013; Cross et al., 2011). The lifetime prevalence rates of SAD for females is $8.0 \%$ and $6 \%$ for males (NIMH, 2017). Asher and colleagues (2018) examined gender differences in a sample of adults $(\mathrm{N}=652)$ in the United States using data from the National Comorbidity Survey-Replication (NCS-R; 2001-2003). Results indicated that females were more likely to have a diagnosis of SAD over 12 months as well as higher rates of impairment compared to males. Further, the study indicated that females diagnosed with SAD were more likely to have a comorbid diagnosis of specific phobia, generalized anxiety disorder, and post-traumatic stress disorder. On the other hand, males with SAD were more likely to have a comorbid diagnosis of substance abuse disorders and conduct disorders (Asher \& Aderka, 2018). Additionally, Asher and Aderka (2018) found that 
over 12 months, females were more likely to discuss their social fears with a medical professional than males. Despite this, there were no gender differences found in the likelihood of hospitalizations due to social fears or the age at which treatment was sought for social anxiety (Asher \& Aderka, 2018). Similarly, Xu and colleagues (2011) utilized data from the United States National Epidemiological Survey on Alcohol and Related Conditions $(\mathrm{N}=43,093)$ to investigate gender differences in SAD. The study results were in line with previous research; females were more likely to report higher scores and greater impairment than males. Further, men were more likely to have comorbid externalizing diagnoses, and women were more likely to have comorbid internalizing disorders (Xu et al., 2012).

Childhood Trauma and Perceived Social Support. Prior research has indicated that childhood trauma can have lasting impacts psychological and physical well-being (Evans et al., 2013). Despite this, not all children who experience childhood trauma develop physical and psychological issues. Some individuals appear to be relatively healthy functioning and do not display symptoms as a result of their trauma (Evans et al., 2013). Research has sought to understand the mechanisms that may be contributing to this variation. Protective factors are attributes that help an individual cope with stressful events in a more effective way and serve to mitigate their impact (APA, 2020). Protective factors can be a shield for an individual experiencing trauma, resulting in less acute mental health outcomes. One such factor that may play an essential role in facilitating this adjustment is social support (Evans et al., 2013; Hyman et al., 2003). Social support can be defined as the interpersonal assistance an individual may receive while they are coping with stressful events (Hyman et al., 2003). Research has indicated that social 
support can serve as a buffer for individuals who have been exposed to trauma and can potentially mitigate the psychological impact. This theory is supported by the stressbuffering model which states that individuals may perceive an event as less stressful if they believe others will provide resources as a means of coping with the traumatic event (Cohen \& Wills, 1985). Further, this buffering effect can aid in facilitating cognitive and emotional processing that results in a mitigated perception of the adverse experience (Hyman et al., 2003; Cohen \& Wills, 1985). Tremblay and colleagues (1999) studied survivors of childhood sexual abuse and found that individuals who perceived their parents to be more supportive reported more positive self-worth and less acute behavioral challenges. Over the years, there has been growing evidence indicating that social support can be a critical moderator of psychological symptoms following sexual abuse (Hyman et al., 2003)., Brewin and colleagues (2000) conducted a meta-analysis among military and civilian populations that were exposed to some form of psychological trauma (Brewin et al., 2000). The study's results suggested that a lack of social support, specifically perceived social support, was the single most reliable predictor of increased traumatic stress symptoms developing within this population. This is in line with other research findings that have indicated that perceived social support can be seen as critical in mitigating the impacts of psychological distress (Brewin et al., 2000; Cohen \& Wills, 1985; Sarason \& Gurung, 2001). Additionally, prior research has demonstrated that an individual's perceived social support is primarily dependent on the strength of the support they believe they are receiving compared with the size of the individual's social network.

Gender Differences in Perceived Social Support. The literature on gender differences in perceived social support displays some mixed results. Ross and Mirowsky 
(1989) conducted a study with 809 individuals aged 18 and 85, with results indicating that women reported higher levels of perceived social support than men. On the other hand, some studies have reported little to no difference across genders (Soman et al., 2016). Despite this, there is a growing consensus suggesting that women both receive and provide more social support than men (Ross \& Mirowsky, 1999; Soman et al., 2016). Research has indicated this may be due to women having a higher likelihood of seeking emotional support and disclosing more frequently, resulting in women perceiving they have more social support (Soman et al., 2016, Kendler et al., 2005). Additionally, Kendler and colleagues (2005) conducted a study with 1,057 pairs of opposite-sex dizygotic twin pairs to assess the relationship between social support and risk for major depression. The study results indicated that women reported higher levels of global social support than their male twin brothers (Kendler et al., 2005).

Perceived Social Support and Social Anxiety. SAD impacts approximately $12.1 \%$ of the United States population every year (Kessler et al., 2005). Prior research has indicated that SAD symptoms are often associated with challenges specific to interpersonal interactions with others, difficulties in forming relationships, and having an extensive social network. Research has noted that social anxiety is also associated with lower perceived social support (Caslyn, et al., 2005; Barnett et al., 2020). Cross-sectional research has demonstrated that individuals with more severe SAD report having lower perceived social support than individuals with less severe SAD. In evaluating the relationship between social support and social anxiety, there has been some debate centering on two specific theories, the first being the social causation model, which indicates that a lack of social support is a causal factor for social anxiety. The second is 
the social selection model, which states that social anxiety is the causal factor for social support levels. Research on these two models led to a reciprocal effects model in which the relationship between social support and social anxiety is mostly reciprocal, with more social anxious individuals perceiving themselves to have less support and the perception of a paucity of social support increasing an individual's social anxiety (Calsyn et al., 2005; Barnett et al., 2020). Prior research has also indicated that perceived social support is far more dependent on the degree of satisfaction an individual feels than the size of an individual's social network (Barnett et al., 2020). Barnett and colleagues (2020) conducted a study with college students $(\mathrm{N}=813)$ to evaluate whether gender differences and the role of communication styles mediates the relationship of social anxiety and perceived social support. The results of the study indicated that social anxiety was associated with less social support through lower expressiveness (Barnett et al., 2020). Similarly, Torgrud and colleagues (2004) collected data from 132 individuals who met DSM-IV criteria for Social Phobia. Participants were administered two measures assessing perceived social support, The Social Support Questionnaire (SSQ) and The Multidimensional Scale of Perceived Social Support (MSPSS) (Torgrud et al., 2004). Results demonstrated that deficits in perceived social support were associated with social phobia. Additionally, the study postulated that lower social support levels associated with social phobia might contribute to the development of comorbid conditions.

Childhood Trauma, Social Anxiety, and Perceived Social Support. Although both perceived social support and childhood trauma have been studied and supporting evidence of correlations between each of these factors and social anxiety have been established, there is a paucity in research examining the relationships amongst all three of 
these factors. Due to perceived social support's relation to both childhood trauma and social anxiety, it is a construct that warrants further investigation as a mediator of the relationship between childhood trauma and social anxiety. No studies to date have examined the impact of perceived social support on the mental health outcomes of individuals who have experienced childhood trauma, and it is possible that having higher perceived social support may inhibit negative outcomes, specifically social anxiety.

Purpose of Study and Research Questions. There is growing evidence of the relationships between childhood trauma and anxiety, childhood trauma and social support, as well as social support and social anxiety. The present study aimed to investigate whether perceived social support serves as a mediator of the relationship between traumatic childhood experiences and social anxiety as well as whether gender moderates the relationship between childhood trauma and social anxiety. Hypotheses are as follows: (1) childhood trauma and social anxiety will be positively correlated, (2) perceived social support will mediate the relationship between traumatic childhood experiences and social anxiety (See Figure 1); and (3) gender will moderate the relationship of childhood trauma and social anxiety, with females showing a stronger relationship between childhood trauma and social anxiety than males (See Figure 2). In the present study traumatic childhood experiences will be evaluated separately by type: emotional abuse (EA), emotional neglect (EN), physical abuse (PA), physical neglect (PN), and sexual abuse (SA). 
Figure 1. Conceptual Model for Hypothesis 2

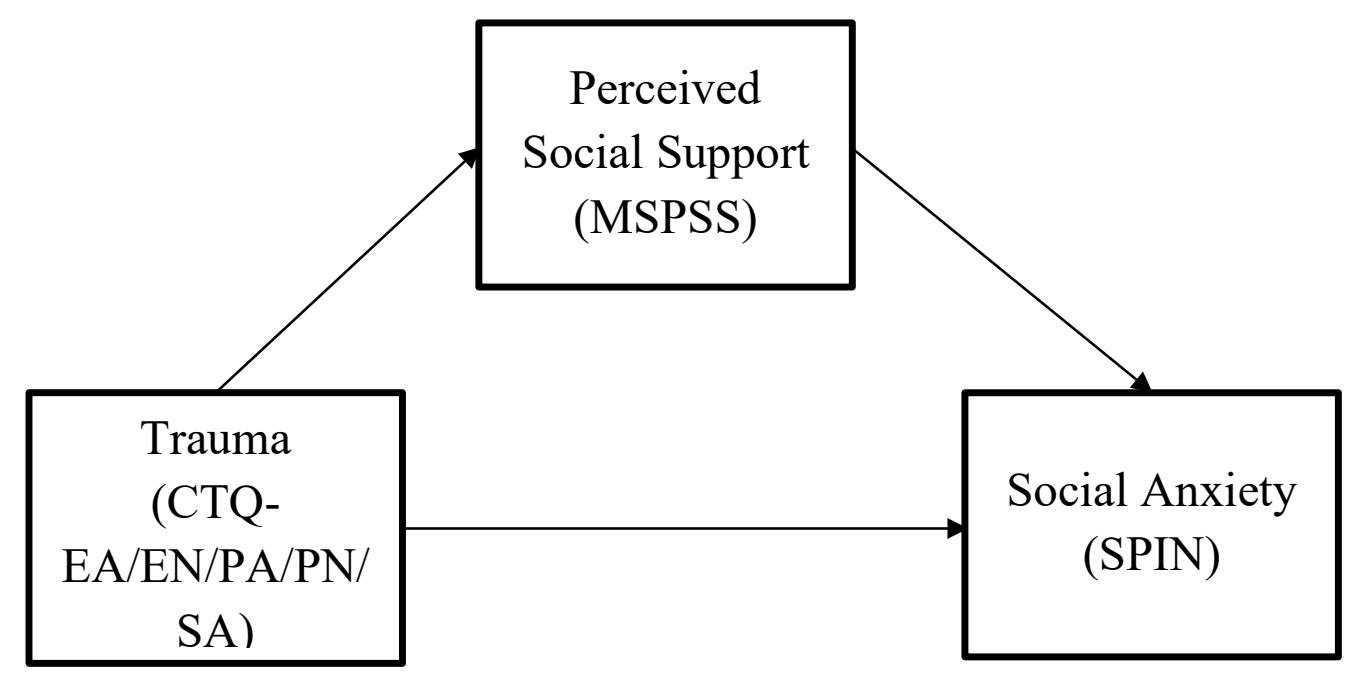

Figure 2. Conceptual Model for Hypothesis 3

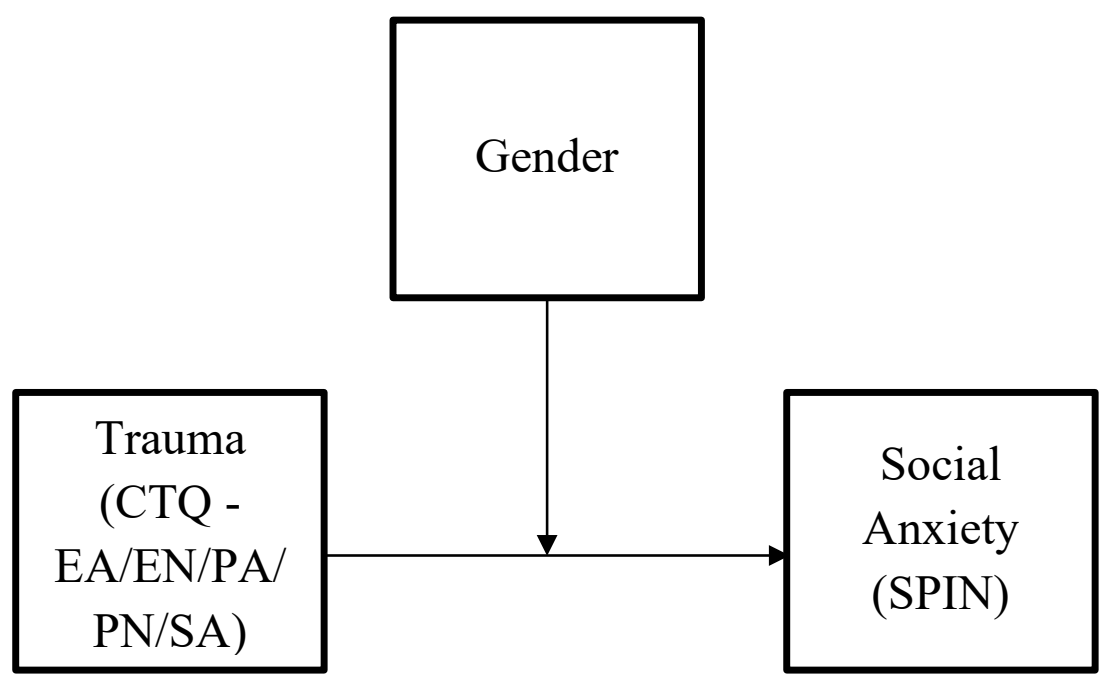

Method

\section{Participants}

Participants $\left(n=221, \mathrm{M}_{\mathrm{age}}=19.5,84.6 \%\right.$ female $)$ were undergraduate students recruited from introductory psychology courses at the University of Rhode Island in the spring of 2018. Additional demographic information is displayed in Table 1. Participants were provided with extra credit in their college course for their participation, and an 
alternate extra credit opportunity was available for those choosing not to participate. Participants completed online questionnaires that were compiled for use in a previous study, including a demographic form and self-report measures of anxiety, childhood trauma, and perceived social support. The questionnaires took approximately $30-45$ minutes to complete.

Table 1. Demographic Information of Overall Sample

\begin{tabular}{lrr}
\hline Variable & $\boldsymbol{N}$ & \multicolumn{2}{c}{$\%$} \\
\hline Ethnicity & & \\
Hispanic or Latinx: & 26 & $11.8 \%$ \\
Not Hispanic or Latinx & 194 & $87.8 \%$
\end{tabular}

\section{Gender}

Female

Male 187

84.6

$34 \quad 15.4$

\begin{tabular}{lrr} 
Race & & \\
White & 173 & 78.3 \\
\hline Black & 24 & 10.9 \\
\hline Asian & 7 & 3.2 \\
American Indian/Alaskan Native & 3 & 1.4 \\
\hline Native Hawaiian/Other Pacific Islander & 1 & 0.5 \\
\hline Multi-racial & 10 & 4.5 \\
\hline Other & 9 & 4.1 \\
\hline & & \\
\hline Age & & \\
18 & 49 & 22.2 \\
\hline 19 & 74 & 33.5 \\
20 & 52 & 23.5 \\
\hline 21 & 31 & 14.0 \\
22 & 8 & 3.6 \\
23 & 3 & 1.4 \\
24 & 4 & 1.8 \\
\hline
\end{tabular}




\section{Measures}

Demographic Form. A form used to assess participant information regarding their age, gender, race, ethnicity, marital status, college classification, extra-curricular activities, and academic achievement. Additionally, the form gathered information regarding the participant's family make-up, background, and history of mental health.

Childhood Trauma Questionnaire (CTQ.) A brief screening tool comprised of 28 self-report items measuring childhood traumatic experiences across five clinical scales (physical, sexual, and emotional abuse, and physical and emotional neglect). Each scale contains five questions and three validity questions. Experiences in childhood and adolescence are rated on a 5-point, Likert-type scale with response options ranging from Never True to Always True $(1=$ Never True; $2=$ Rarely True; $3=$ Sometimes True; $4=$ Often True; $5=$ Always True). The CTQ is one of the most commonly used measures for examining child abuse and neglect in both adolescents and adults and has been wellvalidated across numerous diverse samples (Bernstein \& Fink, 1998; Forde et al., 2012; Karos et al., 2014). Research has consistently shown that the CTQ has high sensitivity across forms of maltreatment and yields high test-retest reliability. (Bernstein et al., 2003). Scores for the CTQ range from 5 to 25. According to the CTQ scoring manual (Bernstein \& Fink, 1998), each subscale is separated into four levels of severity, with each subscale having its own cut-offs as displayed in Table 2. Means, standard deviations, and ranges of the current sample for the CTQ are displayed in Table 3.

The current study used each of the five item subscales: emotional abuse, emotional neglect, sexual abuse, physical abuse, and physical neglect. All of these factors have demonstrated a high degree of internal consistency, e.g., sexual abuse subscale $(\alpha=$ 
.93-.95), emotional neglect subscale $(\alpha=.88-.92)$, emotional abuse subscale $(\alpha=.84$ -

$.89)$, physical abuse subscale $(\alpha=.81-.86)$, and physical neglect subscale $(\alpha=.68-.78)$

(Bernstein \& Fink, 1998).

Table 2. Severity Cut-off Scores for CTQ subscales

\begin{tabular}{lllll}
\hline Scale & $\begin{array}{l}\text { None (or } \\
\text { Minimal) }\end{array}$ & $\begin{array}{l}\text { Low (to } \\
\text { Moderate) }\end{array}$ & $\begin{array}{l}\text { Moderate (to } \\
\text { Severe) }\end{array}$ & $\begin{array}{l}\text { Severe (to } \\
\text { Extreme) }\end{array}$ \\
\hline CTQ-EA & $5-8$ & $9-12$ & $13-15$ & $\geq 16$ \\
CTQ-EN & $5-9$ & $10-14$ & $15-17$ & $\geq 18$ \\
CTQ-PN & $5-7$ & $8-9$ & $10-12$ & $\geq 13$ \\
CTQ-PA & $5-7$ & $8-9$ & $10-12$ & $\geq 13$ \\
CTQ-SA & 5 & $6-7$ & $8-12$ & $\geq 13$ \\
\hline
\end{tabular}

Social Phobia Inventory (SPIN). A brief screening tool comprised of 17 selfreport items measuring the severity of fear, avoidance, and physiological symptoms of social phobia. The SPIN includes statements such as, "I would do anything to avoid being criticized." Participants rate the statements on a 5-point, Likert-type scale ranging from "Not at All" to "Extremely" $(1=$ Not at All; 2= A little bit; $3=$ Somewhat; 4=Very Much; $5=$ Extremely). The current study used the Total Social Phobia Inventory score, which has demonstrated adequate test-retest reliability and a good degree of internal consistency $(\alpha=0.94)$ across populations (KM Connor, et al., 2000). Results for the SPIN are displayed on a 0 to 68 -point scale with higher scores representing higher levels of social anxiety. Scores for the SPIN are divided in to four severity levels; scores between 21 and 30 are considered "mild," scores between 31 and 40 are considered "moderate," scores between 41 and 50 are considered "severe," and scores above 50 are considered "very severe." Means, standard deviations, and ranges of the current sample for the SPIN are displayed in Table 3 . 
Multidimensional Scale of Perceived Social Support (MSPSS). A 12-item selfreport measure that assesses an individual's perceived satisfaction with social support across three specific sources (family, friends and significant others). Each of the 12 items are rated using a 7-point, Likert-type scale with response options ranging from Very Strongly Disagree to Very Strongly Agree ( $1=$ Very Strongly Disagree; $2=$ Strongly Disagree; 3= Mildly Disagree; 4= Neutral; $5=$ Mildly Agree; $6=$ Strongly Agree; $7=$ Very Strongly Agree). Research on the MSPSS has provided strong support for its psychometric properties, and the measure has been validated across a diverse sample of populations, including pregnant women, adolescents living abroad, pediatric residents, psychiatric outpatients, and university undergraduate students (Zimet al.,1988; Cecil et al., 1995). The current study used the Total Multidimensional Scale of Perceived Social Support score, which has also demonstrated very good internal reliability across participant groups $(\alpha=.84)$ (Zimet et al., 1988). Results for the MSPSS are displayed on a 12 to 84-point scale with higher scores indicating higher levels of perceived social support. Means, standard deviations, and ranges of the current sample for the MSPSS are displayed in Table 3.

Table 3. Ranges, Means, and Standard Deviations for Primary Scales in Overall Sample

\begin{tabular}{llllll}
\hline Variable & $\boldsymbol{N}$ & Possible Range & Sample Range & Mean & SD \\
\hline CTQ-EA & 215 & $5-25$ & $5-25$ & 8.29 & 4.3 \\
CTQ-EN & 219 & $5-25$ & $5-25$ & 9.76 & 5.00 \\
CTQ-PN & 215 & $5-25$ & $5-23$ & 7.34 & 3.05 \\
CTQ-PA & 219 & $5-25$ & $5-22$ & 6.30 & 3.14 \\
CTQ-SA & 217 & $5-25$ & $5-25$ & 5.89 & 2.96 \\
MSPSS & 209 & $12-84$ & $12-84$ & 68.58 & 14.65 \\
SPIN & 221 & $0-68$ & $0-68$ & 23.79 & 15.57 \\
\hline
\end{tabular}




\section{Results}

\section{Preliminary Analyses}

In the current sample, scores ranged from "none" to "severe" for CTQ-EA, CTQEN, CTQ-PN, CTQ-PA and CTQ-SA (see Table 4). However, for both CTQ-PA and CTQ-SA, over eighty-five percent of the sample scored "none" (or minimal) trauma. Regarding social anxiety, scores for the SPIN ranged from "non-clinical" to "very severe" (see Table 5). For the MSPSS, scores ranged from 12 "very low social support" to "high social support" (see Table 6).

Table 4. Distribution of CTQ Scores

\begin{tabular}{lllll}
\hline Scale & $\begin{array}{l}\text { None (or } \\
\text { Minimal) } \\
\text { N (\%) }\end{array}$ & $\begin{array}{l}\text { Low (to } \\
\text { Moderate) } \\
\text { N (\%) }\end{array}$ & $\begin{array}{l}\text { Moderate (to } \\
\text { Severe) } \\
\boldsymbol{N}(\%)\end{array}$ & $\begin{array}{l}\text { Severe (to } \\
\text { Extreme) } \\
\boldsymbol{N}(\%)\end{array}$ \\
\hline CTQ-EA & $144(66.98)$ & $38(17.67)$ & $15(6.98)$ & $18(8.37)$ \\
CTQ-EN & $130(59.36)$ & $46(21.00)$ & $23(10.50)$ & $20(9.13)$ \\
CTQ-PN & $137(63.72)$ & $34(15.81)$ & $26(12.09)$ & $18(8.37)$ \\
CTQ-PA & $188(85.84)$ & $8(3.65)$ & $10(4.57)$ & $13(5.94)$ \\
CTQ-SA & $188(86.64)$ & $10(4.61)$ & $16(7.37)$ & $8(3.69)$ \\
\hline
\end{tabular}

Table 5. Distribution of SPIN Scores

\begin{tabular}{llllll}
\hline Scale & $\begin{array}{l}\text { Non- } \\
\text { Clinical }\end{array}$ & $\begin{array}{l}\text { Mild } \\
\text { N(\%) }\end{array}$ & $\begin{array}{l}\text { Moderate } \\
\text { N(\%) }\end{array}$ & $\begin{array}{l}\text { Severe } \\
\boldsymbol{N}(\%)\end{array}$ & $\begin{array}{l}\text { Very } \\
\text { Severe } \\
\boldsymbol{N}(\%)\end{array}$ \\
\hline SPIN & $106(47.96)$ & $40(18.09)$ & $42(19.00)$ & $21(9.50)$ & $12(5.43)$
\end{tabular}

Table 6. Distribution of MSPSS Scores

\begin{tabular}{lllll}
\hline Scale & Very Low & Low & Medium & High \\
& $\boldsymbol{N}(\%)$ & $N(\%)$ & $\boldsymbol{N}(\%)$ & (\%) \\
\hline MSPSS & $33(14.93)$ & $34(15.38)$ & $52(23.53)$ & $90(40.72)$
\end{tabular}


Bivariate analysis revealed significant correlations among the variables of interest, except for sexual abuse (see Table 7). Emotional abuse and emotional neglect were significantly and positively correlated $(\mathrm{r}=.609, p<.01)$. Both variables were also correlated to physical neglect: emotional abuse was positively correlated to physical neglect $(\mathrm{r}=.471, p<.01)$, and emotional neglect exhibited an even stronger positive correlation to physical neglect $(\mathrm{r}=.685, p<.01)$. Furthermore, all variables were significantly and positively correlated to social anxiety except for sexual abuse, such that individuals reporting higher levels of physical and emotional childhood trauma were more likely to report experiencing higher levels of social anxiety. Emotional abuse had the strongest correlation to social anxiety $(\mathrm{r}=.425 p<.01)$, followed by emotional neglect $(\mathrm{r}=.276, p<.01)$, physical neglect $(\mathrm{r}=.242, p<.01)$, and physical abuse $(\mathrm{r}=.174, p<.01)$. Moreover, childhood trauma was significantly and negatively correlated to perceived social support, with individuals reporting higher levels of childhood trauma being more likely to report lower levels of social support. Emotional neglect had the strongest correlation to perceived social support $(\mathrm{r}=-.621, p<.01)$, followed by emotional abuse $(\mathrm{r}=$ $-.488, p<.01)$, physical neglect $(\mathrm{r}=-.467, p<.01)$, physical abuse $(\mathrm{r}=-.367, p<.01)$ and sexual abuse $(\mathrm{r}=-.152, p<.05)$. Likewise, social anxiety and perceived social support were significantly and negatively correlated, such that individuals reporting higher levels of social anxiety were more likely to report lower levels of perceived social support $(r=$ $.317, p<.01)$. 
Table 7. Correlation Matrix

CTQ_EA CTQ_EN CTQ_PN CTQ_PA $\quad$ CTQ_SA MSPSS SPIN

\begin{tabular}{|c|c|c|c|c|c|c|c|}
\hline$C T Q \_E A$ & 1 & $.609^{* *}$ & $.471^{* *}$ & $.616^{* *}$ & $.260^{*}$ & $-.488^{* *}$ & $.425^{* *}$ \\
\hline$C T Q \_E N$ & & 1 & $.685^{* *}$ & $.455^{* *}$ & $.231 * *$ & $-.621^{* *}$ & $.276^{* *}$ \\
\hline$C T Q \_P N$ & & & 1 & $.454 * *$ & $.325^{* *}$ & $-.467^{* *}$ & $.242^{* *}$ \\
\hline$C T Q \_P A$ & & & & 1 & $.427 * *$ & $-.367 * *$ & $.174 * *$ \\
\hline$C T Q \_S A$ & & & & & 1 & $-.152 *$ & .097 \\
\hline MSPSS & & & & & & 1 & $.317 * *$ \\
\hline SPIN & & & & & & & 1 \\
\hline $\begin{array}{l}\text { Note. } \mathrm{N}=2 \\
.01\end{array}$ & & & & & & & \\
\hline
\end{tabular}

An independent samples t-test revealed significant gender differences for physical abuse $(\mathrm{t}(38.21)=-1.65, \mathrm{p}=.11)$ with $\operatorname{men}(M=7.38, S D=4.38)$ reporting higher levels of physical abuse than women $(M=6.10, S D=2.83)$. Levene's test for equality of variances was significant $(F=12.12, p<.001)$, so degrees of freedom were adjusted from 217 to 38.21. Gender differences were also found for emotional neglect $(t(217)=-$ $2.656, \mathrm{p}=.008)$ with men reporting higher levels of emotional neglect $(M=11.82, S D=$ 5.56) than women $(M=9.38, S D=4.81)$, and physical neglect $(\mathrm{t}(38.044)=-1.764, \mathrm{p}=$ $0.09)$ with men reporting higher levels of physical neglect $(M=8.42, S D=3.98)$ than women $(M=7.15, S D=2.82)$. Levene's test for equality of variances was significant $(F=$ $3.83, p=.052$ ), so degrees of freedom were adjusted from 213 to 38.04 . Significant differences between genders were found for social support $(\mathrm{t}(35.080)=1.99, \mathrm{p}=.05)$ with 
women reporting higher levels $(M=69.66, S D=13.41)$ than men $(M=62.39, S D=19.54)$.

Levene's test for equality of variances was significant $(F=10.763, p=.001)$, so degrees of freedom were adjusted from 207 to 35.080. No significant differences between men and women were found emotional abuse $(\mathrm{t}(213)=.004, \mathrm{p}=.997)$, sexual abuse $(\mathrm{t}(215)=$ $.582, \mathrm{p}=.561)$, or social anxiety $(\mathrm{t}(219)=.921, \mathrm{p}=.358)$. Means and standard deviation for variables of interest are presented in Table 8.

Table 8. Means and Standard Deviations for Study Variables by Gender

\begin{tabular}{|c|c|c|c|c|c|c|c|c|c|}
\hline \multirow[t]{2}{*}{ Variable } & \multicolumn{3}{|l|}{ Total } & \multicolumn{3}{|l|}{ Men } & \multicolumn{3}{|c|}{ Women } \\
\hline & Mean & SD & $\mathbf{N}$ & Mean & SD & $\mathbf{N}$ & $\begin{array}{l}\text { Mea } \\
\text { n }\end{array}$ & SD & $\mathbf{N}$ \\
\hline$C T Q \_E A$ & 8.29 & 4.31 & 215 & 8.29 & 4.49 & 31 & 8.29 & 4.29 & 184 \\
\hline$C T Q \_E N$ & 9.76 & 5.00 & 219 & 11.82 & 5.56 & 34 & 9.38 & 4.81 & 185 \\
\hline$C T Q \_P N$ & 7.34 & 3.05 & 215 & 8.42 & 3.98 & 33 & 7.15 & 2.82 & 182 \\
\hline$C T Q \_P A$ & 6.30 & 3.14 & 219 & 7.38 & 4.38 & 34 & 6.10 & 2.83 & 185 \\
\hline$C T Q \_S A$ & 5.96 & 3.01 & 217 & 5.62 & 2.00 & 34 & 5.94 & 3.11 & 183 \\
\hline MSPSS & 68.24 & 15.11 & 209 & 62.39 & 19.54 & 31 & 69.66 & 19.54 & 178 \\
\hline \multirow[t]{2}{*}{ SPIN } & 40.93 & 15.81 & 221 & 21.52 & 14.94 & 34 & 24.20 & 15.68 & 187 \\
\hline & & & & \multicolumn{6}{|c|}{$\begin{array}{l}\text { Note. } \mathrm{N}=221 \text { ( } 2 \text { participants were excluded } \\
\text { due to identifying gender as non-binary) }\end{array}$} \\
\hline
\end{tabular}

\section{Mediation Analysis}

\section{Emotional abuse as predictor}

Regression analyses were conducted in order to examine the hypothesis that perceived social support mediates the relationship between emotional abuse and social anxiety. In step 1 , the regression of emotional abuse on social anxiety was significant, $B$ $=1.54, p<.001$. In step 2 , of the mediation model, the regression of the emotional abuse on social support was also significant, $B=-1.65, p<.001$. Step 3 of the model, the 
regression of social support on social anxiety was also significant, $B=-.16, p=.049$. Step 4 of the analyses revealed that when including social support in the regression analysis, emotional abuse was still a significant predictor of social anxiety, $B=1.28, p<.001$. Therefore, social support was shown to partially mediate the relationship between emotional abuse and social anxiety. These regressions are depicted in Figure 3.

\section{Emotional neglect as predictor}

Regression analyses were also conducted in order to examine the hypothesis that social support mediates the relationship between emotional neglect and social anxiety. In step 1, the regression of emotional neglect on social anxiety was significant $B=.918$, $p<.001$. Step 2 demonstrated that the regression of emotional neglect on social support was significant, $B=-1.79, \mathrm{p}<.001$. Step 3 showed that the regression of social support on social anxiety was significant, $B=-.247 \mathrm{p}=.007$. Step 4 of the analyses revealed that when including social support in the regression analysis, emotional neglect was not a significant predictor of social anxiety $B=.477, \mathrm{p}=.069$. Therefore, social support was shown to fully mediate the relationship between emotional neglect and social anxiety. These regressions are depicted in Figure 4.

\section{Physical abuse as predictor}

Regression analyses were conducted in order to examine the hypothesis that perceived social support mediates the relationship between physical abuse and social anxiety. In Step 1, the regression of physical abuse on social anxiety was significant, $B=.925, p=.008$. Step 2 demonstrated that the regression of physical abuse on social support was significant, $B=-1.68, p<.001$. Step 3 of the model, the regression of social support on social anxiety was also significant, $B=-.309, p<.001$. Step 4 of the analyses 
revealed that when including social support in the regression analysis, physical abuse was no longer a significant predictor of social anxiety, $B=.405, \mathrm{p}=.258$. Therefore, social support was shown to fully mediate the relationship between physical abuse and social anxiety. These regressions are depicted in Figure 5.

\section{Physical neglect as predictor}

Regression analyses were conducted in order to examine the hypothesis that perceived social support mediates the relationship between physical neglect and social anxiety. In step 1, the regression of physical neglect on social anxiety was significant, $B=1.31, p<.001$. Step 2 , of demonstrated that the regression of physical neglect on social support was also significant, $B=-2.08, p<.001$. Step 3, the regression of social support on social anxiety was also significant, $B=-.261, p=.002$. Step 4 of the analyses revealed that when including social support in the regression analysis, physical neglect was still a significant predictor of social anxiety, $B=.766, \mathrm{p}=.0459$. Therefore, social support was shown to partially mediate the relationship between physical neglect and social anxiety. These regressions are depicted in Figure 6.

\section{Sexual abuse as predictor}

Regression analyses were conducted in order to examine the hypothesis that perceived social support mediates the relationship between sexual abuse and social anxiety. In Step 1, the regression of sexual abuse on social anxiety was not significant, $B=.651, \mathrm{p}=.0124$. Thus, the mediation model was not significant, and social support did not mediate the relationship between sexual abuse and social anxiety. 
Figure 3. Results of Regression Analyses for the relationships between Emotional Abuse, Perceived Social Support and Social Anxiety

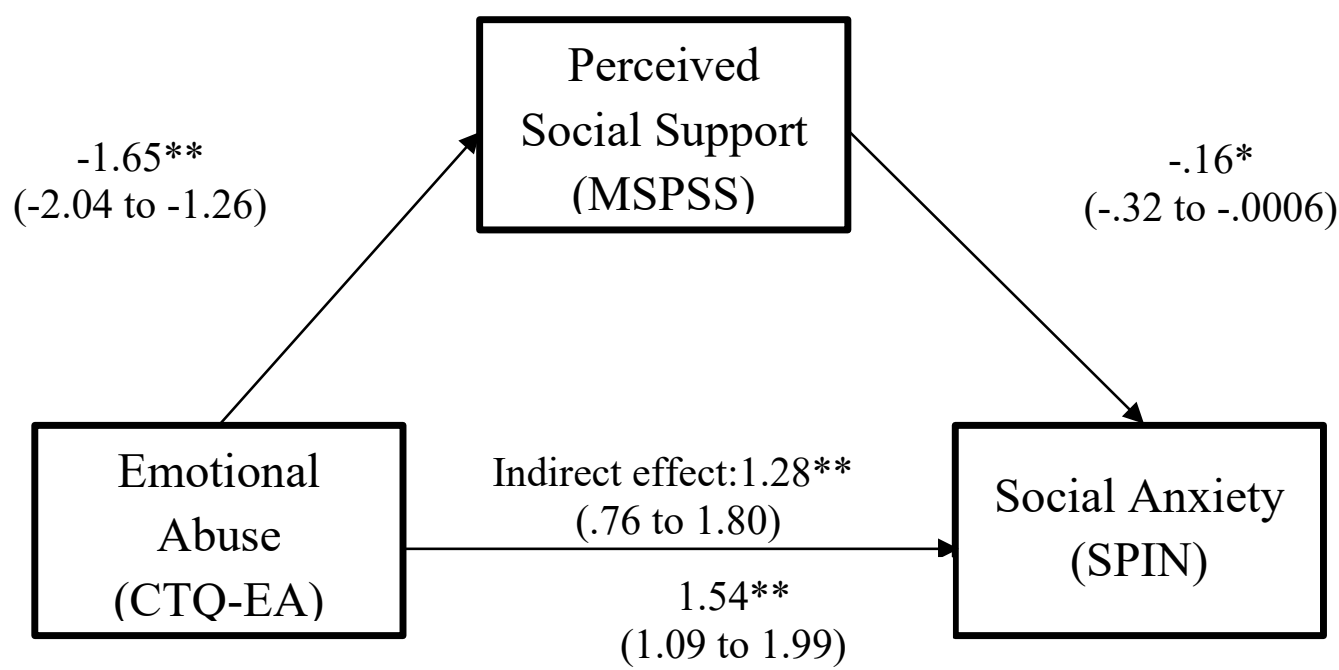

Note. $* p<.05, * * p<.01$

Figure 4. Results of Regression Analyses for the relationships between Emotional Neglect, Perceived Social Support and Social Anxiety

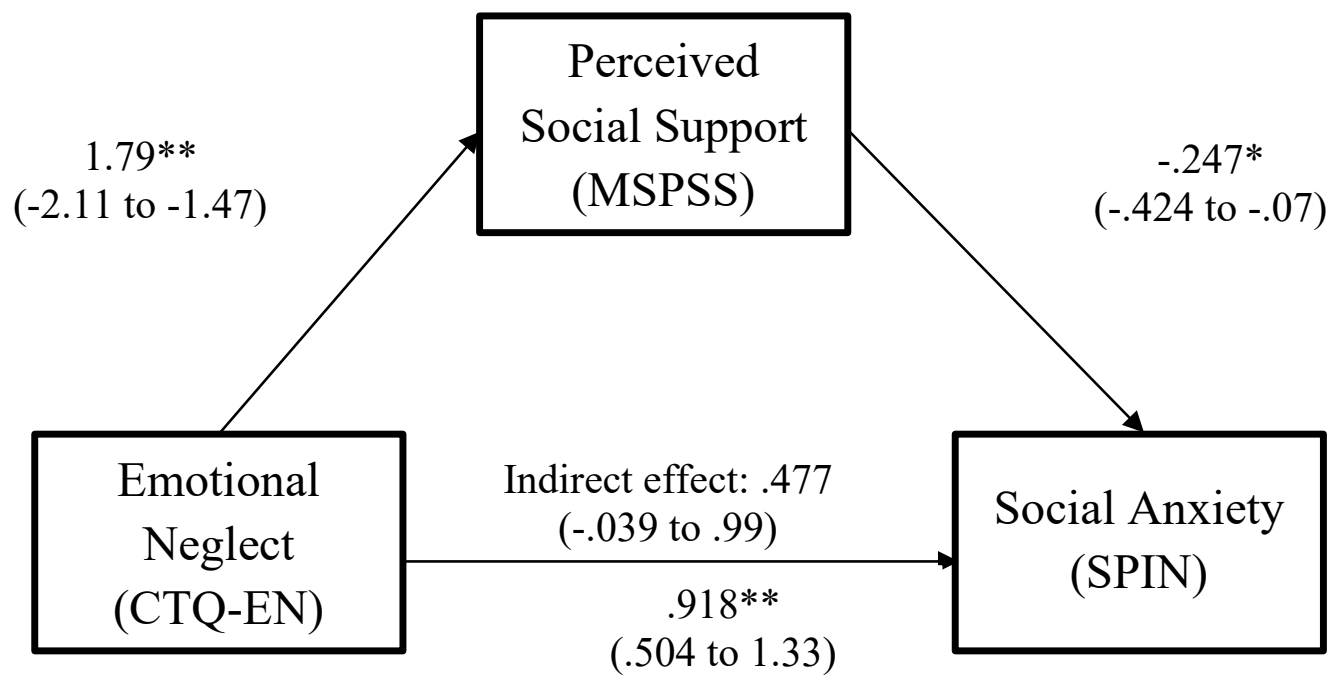

Note. ${ }^{*} p<.05,{ }^{* *} p<.01$ 
Figure 5. Results of Regression Analyses for the relationships between Physical Abuse, Perceived Social Support and Social Anxiety

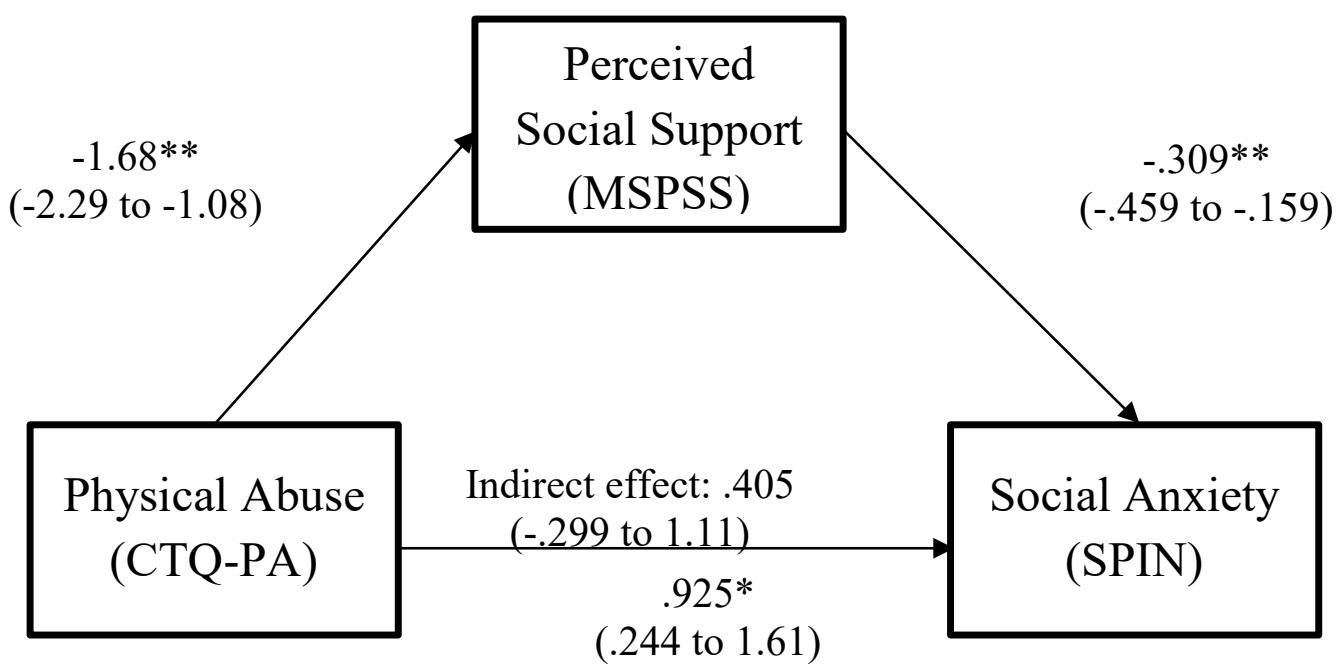

Note. $* p<.05, * * p<.01$

Figure 6. Results of Regression Analyses for the relationships between Physical Neglect, Perceived Social Support and Social Anxiety

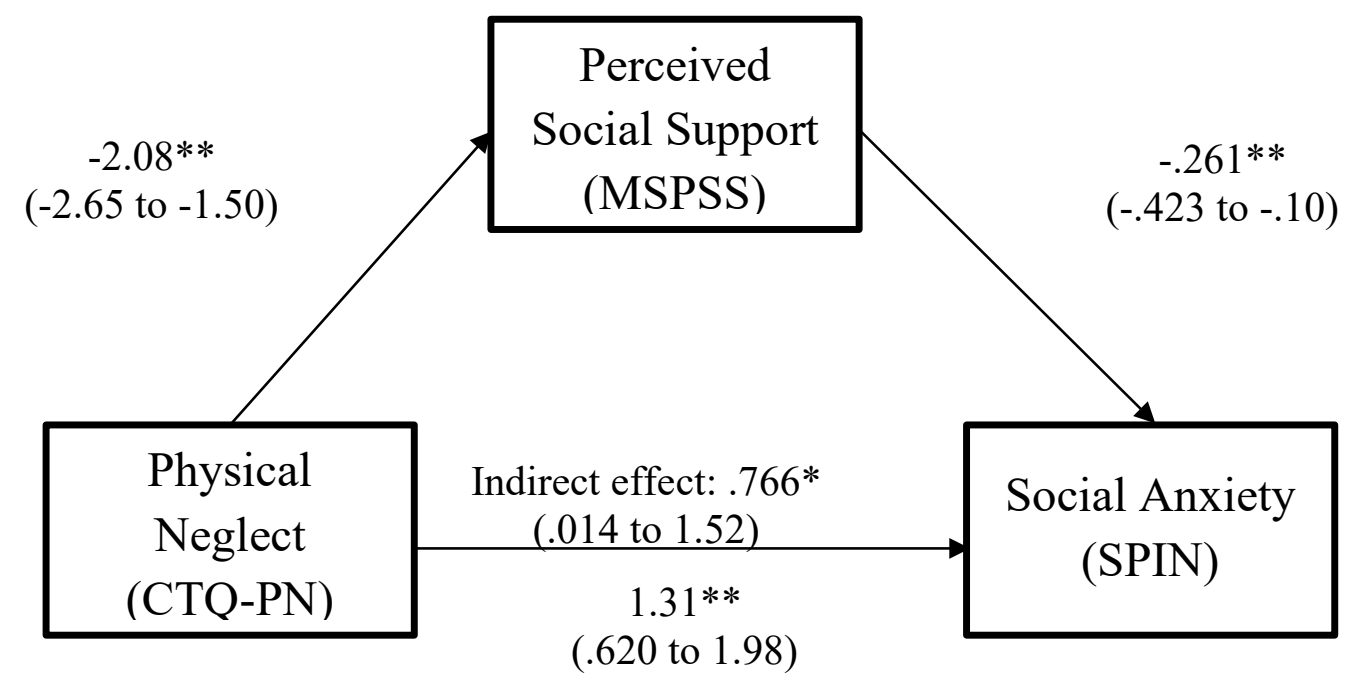

Note. ${ }^{*} p<.05, * * p<.01$ 


\section{Moderation Analyses}

\section{Gender as moderator of emotional abuse and social anxiety}

Regression analyses were conducted in order to examine whether gender moderates the relationship between emotional abuse and social anxiety. In step 1 of the moderation model, results indicated that emotional abuse and gender accounted for approximately $20 \%$ of the variance in social anxiety $\left(R^{2}=.18, F(3,211)=15.91, p<001\right)$. Emotional abuse was a significant predictor of social anxiety $(\operatorname{coeff}=1.61,95 \%$ CI $[1.17$, $2.05], \mathrm{t}=7.22, \mathrm{p}<.001)$, but gender was not $(\operatorname{coeff}=-1.40,95 \% \mathrm{CI}[-7.09,3.75], \mathrm{t}=-.81$, $\mathrm{p}<.421$ ). In step 2 , the interaction term between emotional abuse and gender was examined. Results indicated that the interaction was not significant (coeff $=.47,95 \% \mathrm{CI}$ $[-.76,1.7], \mathrm{t}=.7532, \mathrm{p}=.452)$. Thus, gender did not have a moderating effect on the relationship between emotional abuse and social anxiety.

\section{Gender as moderator of emotional neglect and social anxiety}

Regression analyses were also conducted in order to examine whether gender moderates the relationship between emotional neglect and social anxiety. In step 1 of the moderation model, results indicated that emotional neglect and gender accounted for approximately $9 \%$ of the variance in social anxiety $(\mathrm{DV})\left(R^{2}=.09, F(3,215)=7.67\right.$, $p<.001)$. Emotional neglect was a significant predictor of social anxiety (coeff $=.949$, $95 \%$ CI $[.537,1.36], \mathrm{t}=4.54, \mathrm{p}<.001)$, but gender was not $(\operatorname{coeff}=-4.19,95 \%$ CI $[-7.95$, $-.433], \mathrm{t}=-2.20, \mathrm{p}=.03)$. In step 2 , the interaction term between emotional neglect and gender was examined. Results indicated that the interaction was not significant (coeff $=$ $.471,95 \%$ CI $[-.76,1.7], \mathrm{t}=.753, \mathrm{p}=.45)$. Thus, gender did not have a moderating effect on the relationship between emotional neglect and social anxiety. 


\section{Gender as moderator of physical abuse and social anxiety}

Regression analyses were also conducted in order to examine whether gender moderates the relationship between physical abuse and social anxiety. In step 1 of the moderation model, results indicated that physical abuse and gender accounted for approximately $4 \%$ of the variance in social anxiety $\left(R^{2}=.05, F(4,215)=3.83, p=.011\right)$. Physical abuse was a significant predictor of social anxiety $($ coeff $=.909,95 \%$ CI $[.243$, $1.58], \mathrm{t}=2.69, \mathrm{p}<.008$, but gender was not $(\operatorname{coeff}=-1.99,95 \% \mathrm{CI}[-5.70,1.73], \mathrm{t}=-1.05, \mathrm{p}$ $=.293$ ). In step 2 , the interaction term between physical abuse and gender was examined. Results indicated that the interaction was not significant (coeff $=1.24,95 \%$ CI $[-.19$, $2.68], \mathrm{t}=1.70, \mathrm{p}=.09$ ). Thus, gender did not have a moderating effect on the relationship between physical abuse and social anxiety.

\section{Gender as moderator of physical neglect and social anxiety}

Regression analyses were also conducted in order to examine whether gender moderates the relationship between physical neglect and social anxiety. In step 1 of the moderation model, results indicated that physical neglect and gender accounted for approximately $8 \%$ of the variance in social anxiety $\left(R^{2}=.07, F(3,211)=5.40, p<.001\right)$. Physical neglect was a significant predictor of social anxiety $($ coeff $=1.33,95 \%$ CI [.661, $2.01], \mathrm{t}=3.90, \mathrm{p}<.001)$, but gender was not $(\operatorname{coeff}=-4.36,95 \%$ CI $[-8.13,-.58], \mathrm{t}=-2.28$, $\mathrm{p}=.024)$. In step 2 , the interaction term between physical neglect and gender was examined. Results indicated that the interaction was not significant (coeff $=-.61,95 \% \mathrm{CI}$ $[-2.15, .94], \mathrm{t}=-.77, \mathrm{p}=.44)$. Thus, gender did not have a moderating effect on the relationship between physical neglect and social anxiety. 


\section{Gender as moderator of sexual abuse and social anxiety}

Finally, regression analyses were conducted in order to examine whether gender moderates the relationship between sexual abuse and social anxiety. In step 1 of the moderation model, results indicated that sexual abuse and gender accounted for approximately $1 \%$ of the variance in social anxiety $(\mathrm{DV})\left(R^{2}=.01, F(3,213)=1.06\right.$, $p=.37)$. Sexual abuse was not a significant predictor of social anxiety (coeff $=.478,95 \%$ $\mathrm{CI}[-.237,1.19], \mathrm{t}=1.32, \mathrm{p}=.19)$, as was gender $($ coeff $=-1.54,95 \%$ CI $[-5.28,2.21], \mathrm{t}=$ $-.81, p=.42$. In step 2 , the interaction term between sexual abuse and gender was examined. Results indicated that the interaction was not significant (coeff $=.91,95 \% \mathrm{CI}$ $[-1.86,3.67], \mathrm{t}=.65, \mathrm{p}=.52)$. Thus, gender did not have a moderating effect on the relationship between sexual abuse and social anxiety.

\section{Discussion}

The current study was aimed at expanding the literature regarding the relationship between childhood trauma and social anxiety. As hypothesized, findings indicated significant positive correlations between childhood trauma and social anxiety with one exception. Positive correlations were found for emotional abuse, emotional neglect, physical abuse, and physical neglect, but not for sexual abuse. The lack of a relationship between sexual abuse and social anxiety may be related to prior research indicating that other forms of trauma, particularly emotional neglect and abuse, may be more aligned with the development of social anxiety (Kuo et al., 2011). These correlations between childhood trauma and social anxiety are in line with previous findings.

Significant negative correlations were found between perceived social support and emotional abuse, emotional neglect, physical abuse, physical neglect and sexual 
abuse. These findings support previous research indicating that symptoms associated with many types of childhood trauma are more acute with a lack of social support (Brewin et al., 2000; Cohen \& Wills, 1985; Sarason \& Gurung, 2001). Furthermore, perceived social support and social anxiety were also found to be significantly negatively correlated and in agreement with previous research (Caslyn, et al., 2005; Barnett et al., 2020).

The present study's second hypothesis proposed that perceived social support would mediate the relationship between childhood trauma and social anxiety. This study, to our knowledge, was the first to explore perceived social support as a mediator of this relationship. Findings revealed that emotional and physical abuse as well as emotional and physical neglect were significant predictors of perceived social support. Further, perceived social support was a significant predictor of social anxiety; therefore, perceived social support served as a mediator for the relationship between childhood trauma and social anxiety. These findings support previous research indicating that more acute symptoms of childhood trauma are associated with a lack of perceived social support. Furthermore, these findings support the role of perceived social support in the development and maintenance of social anxiety. In line with previous research the current study showed that perceived social support can serve as a buffer for individuals who have been exposed to specific areas of childhood trauma. Moreover, this study demonstrated that perceived social support can potentially mitigate the psychological impact of social anxiety.

The present study also hypothesized that gender would moderate the relationship between childhood trauma and social anxiety. Based on previous research, gender differences in childhood trauma were expected, such that women would report higher 
levels of trauma compared with men (Vahl et., al, 2016). Findings revealed gender differences among emotional neglect, physical neglect, and physical abuse with men endorsing higher levels of trauma compared with women. Contrary to previous research, however, there were no significant gender differences in emotional abuse. The findings of higher levels of physical abuse endorsed by men (vs. women) supports previous findings from studies conducted with clinical populations and individuals who are part of disadvantaged groups (Thompson et al., 2004). The findings in this study expand the literature, demonstrating that men may experience higher levels of physical abuse in the general population, although this abuse does not necessarily translate to more acute levels of social anxiety. Future research should explore how higher levels of physical abuse, physical neglect, and emotional neglect may impact men's mental health and well-being and seek to identify mechanisms that may be acting as mediating factors between these specific forms of trauma and social anxiety. However, contrary to previous research, degree of social anxiety did not differ by gender. Therefore, gender did not moderate the relationship between trauma and social anxiety. Previous research has found emotional abuse to be a strong predictor of social anxiety and that women report higher levels of emotional abuse (Bishop, et al., 2014; Vahl et al., 2016). Despite this, we did not find gender differences in emotional abuse in the present study, and accordingly, did not find moderation by gender. Regarding gender differences in perceived social support, results demonstrated gender differences, with women reporting higher levels of perceived social support than men. This finding supports the literature regarding perceived social support prevalence, in which there is a growing consensus that women both receive and provide more social support than men (Ross \& Mirowsky, 1999; Soman et al., 2016). 


\section{Limitations}

While the current study has contributed to the literature regarding childhood trauma, social anxiety, and perceived social support, there are several limitations to consider. First, the current sample was largely homogeneous (84.6\% female, $78.3 \%$ White, $87.8 \%$ Non-Hispanic). All participants in the study were recruited from a single university located in the northeastern United States through undergraduate psychology courses. The homogenous nature of the sample may have impacted the ability of finding significant differences between genders, possibly leading to the lack of variability in levels of reported trauma (i.e., $84.7 \%$ reported "none or minimal" to "low" emotional abuse). There was low endorsement of clinical levels of "moderate" to "severe" childhood trauma across trauma types, with physical neglect having the highest rate (20.5\% endorsed moderate to severe) and emotional neglect having the second highest rate with (19.6\% endorsed moderate to severe). Further, this factor of homogeneity makes it challenging to generalize the results to a broader population. Future research should utilize a random sampling method with a goal of having equal group sizes by gender. Additionally, future research should examine the relationship between trauma, perceived social support and social anxiety in samples with ratings of more severe levels of childhood trauma. These limitations may be addressed by utilizing a wider geographic sample, as well as incorporating clinical samples to have more heterogeneity and enhance generalizability.

Moreover, it is also possible that there are limitations to the measures used in the current study. The childhood trauma measure, the CTQ, is a self-reported, retrospective measure of childhood traumatic experiences. While the CTQ is one of the most utilized 
measures for examining child abuse and neglect and has been well-validated across numerous diverse samples including college undergraduates, responses are vulnerable to recall biases or distorted memories due to the lapse in time. The retrospective component of this measure may be related to the lower reporting of traumatic experiences in the current study. Future studies should consider utilizing additional reports by health professionals or using structured clinical or life event interviews in efforts to ensure accurate reports of trauma.

Regarding social anxiety, the SPIN is also a self-reported measure, which makes it vulnerable to response bias. Although this measure is often used by researchers to measure social anxiety and has demonstrated a good degree of internal consistency, it was the only measure used to assess social anxiety in the current study. Additionally, because the SPIN was one of the final measures in the questionnaire packet, participants may have experienced testing fatigue, limiting their ability to fully attend to all of the items when completing the measure.

In addition, the measurement of perceived social support, the MSPSS, was a selfreported measure, again increasing risk of response bias. Although this measure has been validated across a diverse sample, it is possible that it did not fully capture participants' experience of perceived social support. Perceived social support is multi-faceted and includes a range of components and individuals. Therefore, the MSPSS may not have addressed the components of perceived social support that may be specifically associated with childhood trauma and social anxiety. Future research should consider additional measures to assess perceived social support or semi-structured interviews to fully assess levels of perceived social support. 


\section{Future Directions}

The present study investigated several important questions regarding the relationship of childhood trauma, perceived social support, and social anxiety and contributed to the literature regarding gender differences in childhood trauma. The results indicated that many types of childhood trauma (emotional abuse, physical abuse, emotional neglect, and physical neglect) were significant predictors of perceived social support. Further, perceived social support was a significant predictor of social anxiety and, furthermore, was found to mediate the relationship between childhood trauma and social anxiety. These findings demonstrate a growing need for interventions specifically tailored for survivors of childhood trauma to incorporate strategies that would increase individuals' access to resources and social supports in their communities. Furthermore, results revealed gender differences among physical abuse, emotional neglect, and physical neglect, with men endorsing higher levels of trauma compared to women. These results bring to light that it is essential to focus on developing interventions and preventative programs specifically targeting male youth and adults who have been victims of trauma. Despite these findings, gender was not found to be a moderator of the relationship between childhood trauma and social anxiety.

Although the present study has contributed to the existing literature, there are various ways to expand and improve the current research. Future research should utilize a more heterogeneous sample, with a focus on exploring a more nuanced view of gender identities and representation of ethnic and racial groups. Further, researchers should consider expanding to a more diverse research methods approach that utilizes both selfreport data via semi-structured interviews and health history reports to gain a more 
comprehensive assessment of childhood trauma, perceived social support, and social anxiety. Additionally, it may also be beneficial for future studies to evaluate other specific types of anxiety disorders and perceived social support across anxiety disorders. Moreover, other possible mediators of the relationship between childhood trauma and social anxiety (e.g., resilience) should be examined.

The current study found that men reported higher levels of childhood physical abuse, emotional neglect, and physical neglect, which demonstrates the need for future research to examine risk and protective factors for mental wellness, such as the impact of gender roles in our society. While the literature on gender differences in perceived social support is mixed, there is growing evidence that women typically seek out emotional support and disclose more frequently, resulting in higher perceived social support. Further research should consider exploring gender differences in childhood trauma, perceived social support, and social anxiety with larger and more diverse samples in order to attain more conclusive and generalizable results.

\section{Conclusion}

In summation, findings indicate that there are significant associations among childhood trauma, perceived social support, and social anxiety. Furthermore, perceived social support mediated the relationship between childhood trauma and social anxiety. Future research should investigate additional risk factors and protective factors that may be associated with social anxiety. Gender was not found to moderate the relationship between childhood trauma and social anxiety, although some gender differences were found in childhood trauma. Specifically, men reported higher levels of physical abuse, emotional neglect, and emotional abuse compared with women. Current findings did not 
support previous findings of women reporting higher emotional abuse. A replication and extension of the current study would help to inform treatment for children who have experienced trauma, as well as aid in developing preventative interventions for social anxiety. 


\section{Bibliography}

Alink, L. R., \& Egeland, B. (2013). The roles of antisocial history and emerging adulthood developmental adaption in predicting adult antisocial behavior. Aggressive behavior, 39(2), 131-140. https://doi.org/10.1002/ab.21464.

American Psychiatric Association. (2000). DSM IV-TR: diagnostic and statistical manual of mental disorders - text revision (4th ed.). Washington, DC: American Psychiatric Association.

American Psychiatric Association. (2013). Diagnostic and statistical manual of mental disorders (5 ${ }^{\text {th }}$ ed.). Arlington, VA: American Psychiatric Publishing.

Asher, M., \& Aderka, I. M. (2018). Gender differences in social anxiety disorder. Journal of clinical psychology, 74(10), 1730-1741. https://doi.org/10.1002/jclp.22624

Barnett, M. D., Maciel, I. V., Johnson, D. M., \& Ciepluch, I. (2020). Social Anxiety and Perceived Social Support: Gender Differences and the Mediating Role of Communication Styles. Psychological Reports.

Beilharz, J. E., Paterson, M., Fatt, S., Wilson, C., Burton, A., Cvejic, E, Vollmer-Conna, U. (2020). The impact of childhood trauma on psychosocial functioning and physical health in a non-clinical community sample of young adults. Australian \& New Zealand Journal of Psychiatry, 54(2), 185-194. https://doi.org/10.1177/0004867419881206

Bernstein, D. P., \& Fink, L. (1998). Childhood Trauma Questionnaire: A retrospective self-report manual. Orlando: Psychological Corporation.

Bernstein, D. P., Stein, J. A., Newcomb, M. D., Walker, E., Pogge, D., Ahluvalia, T., Stokes, J., Handelsman, L., Medrano, M., Desmond, D., \& Zule, W. (2003). 
Development and validation of a brief screening version of the Childhood Trauma Questionnaire. Child abuse \& neglect, 27(2), 169-190.

https://doi.org/10.1016/s0145-2134(02)00541-0

Bremne, J. D., \& Vermetten, E. (2001). Stress and development: behavioral and biological consequences. Development and psychopathology, 13(3), 473-489. https://doi.org/10.1017/s0954579401003042

Brewin, C. R., Andrews, B., \& Valentine, J. D. (2000). Meta-analysis of risk factors for posttraumatic stress disorder in trauma-exposed adults. Journal of consulting and clinical psychology, 68(5), 748-766. https://doi.org/10.1037//0022-006x.68.5.748

Bishop, M., Rosenstein, D., Bakelaar, S. et al. An analysis of early developmental trauma in social anxiety disorder and posttraumatic stress disorder. Ann Gen Psychiatry 13, 16 (2014). https://doi.org/10.1186/1744-859X-13-16

Bruch, M. A., \& Heimberg, R. G. (1994). Differences in perceptions of parental and personal characteristics between generalized and nongeneralized social phobics. Journal of Anxiety Disorders, 8(2), 155-

168. https://doi.org/10.1016/0887-6185(94)90013-2

Calsyn, R. J., Winter, J. P., \& Burger, G. K. (2005). The relationship between social anxiety and social support in adolescents: a test of competing causal models. Adolescence, 40(157), 103-113.

Carr, C. P., Martins, C. M., Stingel, A. M., Lemgruber, V. B., \& Juruena, M. F. (2013). The role of early life stress in adult psychiatric disorders: a systematic review according to childhood trauma subtypes. The Journal of nervous and mental disease, 201(12), 1007-1020. https://doi.org/10.1097/NMD.0000000000000049 
Cecil, H., Stanley, M. A., Carrion, P. G., \& Swann, A. (1995). Psychometric properties of the MSPSS and NOS in psychiatric outpatients. Journal of clinical psychology, 51(5), 593-602. https://doi.org/10.1002/10974679(199509)51:5<593::aid-jclp2270510503>3.0.co;2-w

Clark, D. M. and Wells, A. (1995). A cognitive model of social phobia. In Heimberg, R. G., Liebowitz, M. R., Hope, D. A. and Schneier, F. R. (Eds.), Social Phobia: diagnosis, assessment and treatment (pp. 69-93). New York: Guilford Press

Cohen, S., \& Wills, T. A. (1985). Stress, social support, and the buffering hypothesis. Psychological Bulletin, 98(2), 310-357. https://doi.org/10.1037/00332909.98.2.310

Connor, K. M., Davidson, J. R., Churchill, L. E., Sherwood, A., Foa, E., \& Weisler, R. H. (2000). Psychometric properties of the Social Phobia Inventory (SPIN). New selfrating scale. The British journal of psychiatry: the journal of mental science, 176, 379-386. https://doi.org/10.1192/bjp.176.4.379

Copeland, W. E., Keeler, G., Angold, A., \& Costello, E. J. (2007). Traumatic events and posttraumatic stress in childhood. Archives of general psychiatry, 64(5), 577-584. https://doi.org/10.1001/archpsyc.64.5.577

Cross, S. E., Hardin, E. E., \& Gercek-Swing, B. (2011). The What, How, Why, and Where of Self-Construal. Personality and Social Psychology Review, 15(2), 142179. https://doi.org/10.1177/1088868310373752

Cuming, S., \& Rapee, R. M. (2010). Social anxiety and self-protective communication style in close relationships. Behaviour research and therapy, 48(2), 87-96. https://doi.org/10.1016/j.brat.2009.09.010 
Dell'Osso, L., Abelli, M., Pini, S., Carpita, B., Carlini, M., Mengali, F., Tognetti, R., Rivetti, F., \& Massimetti, G. (2015). The influence of gender on social anxiety spectrum symptoms in a sample of university students. Rivista di psichiatria, 50(6), 295-301. https://doi.org/10.1708/2098.22688

DuMont, K. A., Widom, C. S., \& Czaja, S. J. (2007). Predictors of resilience in abused and neglected children grown-up: the role of individual and neighborhood characteristics. Child abuse \& neglect, 31(3), 255-274. https://doi.org/10.1016/j.chiabu.2005.11.015

Evans, S. E., Steel, A. L., \& DiLillo, D. (2013). Child maltreatment severity and adult trauma symptoms: does perceived social support play a buffering role? Child abuse \& neglect, 37(11), 934-943. https://doi.org/10.1016/j.chiabu.2013.03.005

Felitti, V. J., Anda, R. F., Nordenberg, D., Williamson, D. F., Spitz, A. M., Edwards, V., Koss, M. P., \& Marks, J. S. (1998). Relationship of childhood abuse and household dysfunction to many of the leading causes of death in adults. The Adverse Childhood Experiences (ACE) Study. American journal of preventive medicine, 14(4), 245-258. https://doi.org/10.1016/s0749-3797(98)00017-8

Fisher, H., Morgan, C., Dazzan, P., Craig, T. K., Morgan, K., Hutchinson, G., Jones, P. B., Doody, G. A., Pariante, C., McGuffin, P., Murray, R. M., Leff, J., \& Fearon, P. (2009). Gender differences in the association between childhood abuse and psychosis. The British journal of psychiatry: the journal of mental science, 194(4), 319-325. https://doi.org/10.1192/bjp.bp.107.047985

Forde, D.R., Baron, S.W., Scher, C.D., \& Stein, M.B. (2012). Factor structure and reliability of the Childhood Trauma Questionnaire and prevalence estimates of 
trauma for male and female street youth. Journal of Interpersonal Violence, 27(2), 364-379.

Goldsmith, R. E., Barlow, M. R., \& Freyd, J. J. (2004). Knowing and not knowing about trauma: Implications for therapy. Psychotherapy: Theory, Research, Practice, Training, 41(4), 448-463. https://doi.org/10.1037/0033-3204.41.4.448

Gwadz, M. V., Nish, D., Leonard, N. R., \& Strauss, S. M. (2007). Gender differences in traumatic events and rates of post-traumatic stress disorder among homeless youth. Journal of Adolescence, 30(1), 117

129. https://doi.org/10.1016/j.adolescence.2006.01.004

Hayes, A. F. (2017). Introduction to mediation, moderation, and conditional process analysis: regression-based approach ( $2^{\text {nd }}$ Edition). New York, NY: The Guilford Press.

Heim, C., \& Nemeroff, C. B. (2001). The role of childhood trauma in the neurobiology of mood and anxiety disorders: preclinical and clinical studies. Biological psychiatry, 49(12), 1023-1039. https://doi.org/10.1016/s0006-3223(01)01157-x

Heimberg, Richard G, Brozovich, Faith A, \& Rapee, Ronald M. (2014). Chapter 24 - A Cognitive-Behavioral Model of Social Anxiety Disorder. In Social Anxiety (Third ed., pp. 705-728). Elsevier.

Higgins, D. J., \& McCabe, M. P. (2000). Relationships between different types of maltreatment during childhood and adjustment in adulthood. Child maltreatment, 5(3), 261-272. https://doi.org/10.1177/1077559500005003006

Huh, H. J., Kim, K. H., Lee, H. K., \& Chae, J. H. (2017). The relationship between childhood trauma and the severity of adulthood depression and anxiety symptoms 
in a clinical sample: The mediating role of cognitive emotion regulation strategies. Journal of affective disorders, 213, 44-50.

https://doi.org/10.1016/j.jad.2017.02.009

Hyman, S.M., Gold, S.N. \& Cott, M.A. Forms of Social Support That Moderate PTSD in Childhood Sexual Abuse Survivors. Journal of Family Violence 18, 295-300 (2003). https://doi.org/10.1023/A:1025117311660

Karos, K., Niederstrasser, N., Abidi, L., Bernstein, D.P., \& Bader, K. (2014). Factor structure, reliability, and known groups validity of the German version of the Childhood Trauma Questionnaire (Short-Form) in Swiss patients and nonpatients. Journal of Child Sexual Abuse, 23, 418-430.

Kendler, Kenneth S, Myers, John, \& Prescott, Carol A. (2005). Sex Differences in the Relationship Between Social Support and Risk for Major Depression: A Longitudinal Study of Opposite-Sex Twin Pairs. American Journal of Psychiatry, 162(2), 250-256.

Kessler RC, Chiu WT, Demler O, Merikangas KR, Walters EE. Prevalence, severity, and comorbidity of 12-month DSM-IV disorders in the National Comorbidity Survey Replication. Archives of General Psychiatry. 2005;62:617-27.

Klest, B. (2012). Childhood trauma, poverty, and adult victimization. Psychological Trauma: Theory, Research, Practice, and Policy, 4(3), 245 251. https://doi.org/10.1037/a0024468

Kuo, J. R., Goldin, P. R., Werner, K., Heimberg, R. G., \& Gross, J. J. (2011). Childhood trauma and current psychological functioning in adults with social anxiety 
disorder. Journal of anxiety disorders, 25(4), 467-473.

https://doi.org/10.1016/j.janxdis.2010.11.011

Marx, M., Young, S. Y., Harvey, J., Rosenstein, D., \& Seedat, S. (2017). An Examination of Differences in Psychological Resilience between Social Anxiety Disorder and Posttraumatic Stress Disorder in the Context of Early Childhood

Trauma. Frontiers in psychology, 8, 2058. https://doi.org/10.3389/fpsyg.2017.02058

McLean, C. P., Asnaani, A., Litz, B. T., \& Hofmann, S. G. (2011). Gender differences in anxiety disorders: prevalence, course of illness, comorbidity and burden of illness. Journal of psychiatric research, 45(8), 1027-1035.

https://doi.org/10.1016/j.jpsychires.2011.03.006

Middlebrooks JS, Audage NC (2008) The effects of childhood stress on health across the lifespan. Atlanta, GA: Centers for Disease Control \& Prevention, National Center for Injury Prevention \& Control.

Neff, L. A., \& Karney, B. R. (2005). Gender differences in social support: a question of skill or responsiveness? Journal of personality and social psychology, 88(1), 7990. https://doi.org/10.1037/0022-3514.88.1.79

NIMH (2017). Any Anxiety Disorder. Retrieved from https://www.nimh.nih.gov/health/statistics/any-anxiety-disorder.shtml

Pears, K. C., Kim, H. K., \& Fisher, P. A. (2008). Psychosocial and cognitive functioning of children with specific profiles of maltreatment. Child abuse \& neglect, 32(10), 958-971. https://doi.org/10.1016/j.chiabu.2007.12.009

Poole, J. C., Dobson, K. S., \& Pusch, D. (2017). Anxiety among adults with a history of childhood adversity: Psychological resilience moderates the indirect effect of 
emotion dysregulation. Journal of affective disorders, 217, 144-152.

https://doi.org/10.1016/j.jad.2017.03.047

Pruessner, M., King, S., Vracotas, N., Abadi, S., Iyer, S., Malla, A. K., Shah, J., \& Joober, R. (2019). Gender differences in childhood trauma in first episode psychosis: Association with symptom severity over two years. Schizophrenia research, 205, 30-37. https://doi.org/10.1016/j.schres.2018.06.043

Roohafza, H. R., Afshar, H., Keshteli, A. H., Mohammadi, N., Feizi, A., Taslimi, M., \& Adibi, P. (2014). What's the role of perceived social support and coping styles in depression and anxiety? Journal of research in medical sciences : the official journal of Isfahan University of Medical Sciences, 19(10), 944-949.

Rosenthal, B. S., Wilson, W. C., \& Futch, V. A. (2009). Trauma, protection, and distress in late adolescence: a multi-determinant approach. Adolescence, 44(176), 693703.

Ross, C. E., \& Mirowsky, J. (1989). Explaining the social patterns of depression: control and problem solving--or support and talking? Journal of health and social behavior, 30(2), 206-219.Sarason, B. R., Sarason, I. G., \& Gurung, R. A. R. (2001). Close personal relationships and health outcomes: A key to the role of social support. In B. R. Sarason, \& S. W. Duck (Eds.), Personal relationships: Implications for clinical and community psychology (pp. 15-43). New York: Wiley.

Sarason, B. R., Sarason, I. G., \& Gurung, R. A. R. (2001). Close personal relationships and health outcomes: A key to the role of social support. In B. R. Sarason \& S. 
Duck (Eds.), Personal relationships: Implications for clinical and community psychology (p. 15-41). John Wiley \& Sons Ltd.

Schäfer, I., Langeland, W., Hissbach, J., Luedecke, C., Ohlmeier, M. D., Chodzinski, C., Kemper, U., Keiper, P., Wedekind, D., Havemann-Reinecke, U., Teunissen, S., Weirich, S., Driessen, M., \& TRAUMAB-Study group (2010). Childhood trauma and dissociation in patients with alcohol dependence, drug dependence, or both-A multi-center study. Drug and alcohol dependence, 109(1-3), 84-89. https://doi.org/10.1016/j.drugalcdep.2009.12.012

Sciaraffa, M. A., Zeanah, P. D., \& Zeanah, C. H. (2018). Understanding and promoting resilience in the context of adverse childhood experiences. Early Childhood Education Journal, 46(3), 343-353. https://doiorg.uri.idm.oclc.org/10.1007/s10643-017-0869-3

Smith, C. A., Park, A., Ireland, T. O., Elwyn, L., \& Thornberry, T. P. (2013). Long-term outcomes of young adults exposed to maltreatment: the role of educational experiences in promoting resilience to crime and violence in early adulthood. Journal of interpersonal violence, 28(1), 121-156. https://doi.org/10.1177/0886260512448845

Soenke, Melissa, Hahn, Kathryn S, Tull, Matthew T, \& Gratz, Kim L. (2009). Exploring the Relationship Between Childhood Abuse and Analogue Generalized Anxiety Disorder: The Mediating Role of Emotion Dysregulation. Cognitive Therapy and Research, 34(5), 401-412.

Soman, S., Bhat, S. M., Latha, K. S., \& Praharaj, S. K. (2016). Gender differences in perceived social support and stressful life events in depressed patients. East Asian 
Archives of Psychiatry, 26(1), 22-29. Retrieved from

http://uri.idm.oclc.org/login?url=https://search-proquest-

com.uri.idm.oclc.org/docview/1786576233?accountid=28991

Spenrath, M. A., Clarke, M. E., \& Kutcher, S. (2011). The science of brain and biological development: Implications for mental health research, practice and policy. Journal of the Canadian Academy of Child and Adolescent Psychiatry / Journal de l'Académie Canadienne de Psychiatrie de l'enfant et de l'adolescent, 20(4), 298-305. Retrieved from http://search.ebscohost.com.uri.idm.oclc.org/login.aspx?direct=true\&db=psyh\&A $\mathrm{N}=2011-26504-005 \&$ site $=$ ehost-live $\&$ scope $=$ site

Thompson, M. P., Kingree, J. B., \& Desai, S. (2004). Gender differences in long-term health consequences of physical abuse of children: data from a nationally representative survey. American journal of public health, 94(4), 599-604. https://doi.org/10.2105/ajph.94.4.599

Tolin, D. F., \& Foa, E. B. (2006). Sex differences in trauma and posttraumatic stress disorder: a quantitative review of 25 years of research. Psychological bulletin, 132(6), 959-992. https://doi.org/10.1037/0033-2909.132.6.959

Torgrud, L. J., Walker, J. R., Murray, L., Cox, B. J., Chartier, M., \& Kjernisted, K. D. (2004). Deficits in perceived social support associated with generalized social phobia. Cognitive behaviour therapy, 33(2), 87-96.

https://doi.org/10.1080/16506070410029577 
Tremblay, C., Hebert, M., \& Piche, C. (1999). Coping strategies and social support as mediators of consequences in child sexual abuse victims, Child Abuse and Neglect, 23(9), 929-945. doi:10.1016/S0145-2134(99)00056-3

U.S. Department of Health \& Human Services, Administration for Children and Families, Administration on Children, Youth and Families, Children's Bureau. (2019). Child Maltreatment 2017.

Vahl, P., van Damme, L., Doreleijers, T., Vermeiren, R., \& Colins, O. (2016). The unique relation of childhood emotional maltreatment with mental health problems among detained male and female adolescents. Child abuse \& neglect, 62, 142150. https://doi.org/10.1016/j.chiabu.2016.10.008

Xu, Y., Schneier, F., Heimberg, R. G., Princisvalle, K., Liebowitz, M. R., Wang, S., \& Blanco, C. (2012). Gender differences in social anxiety disorder: Results from the national epidemiologic sample on alcohol and related conditions. Journal of Anxiety Disorders, 26(1), 12-19. doi:10.1016/j.janxdis.2011.08.006

Zimet, G. D., Powell, S. S., Farley, G. K., Werkman, S., \& Berkoff, K. A. (1990). Psychometric characteristics of the Multidimensional Scale of Perceived Social Support. Journal of personality assessment, 55(3-4), 610-617. https://doi.org/10.1080/00223891.1990.9674095 